\title{
Review Article \\ Epidemiology of Dementia among the Elderly in Sub-Saharan Africa
}

\author{
Olaniyi O. Olayinka ${ }^{1}$ and Nadine N. Mbuyi ${ }^{2}$ \\ ${ }^{1}$ Department of Neurology and Psychiatry and Department of Environmental and Occupational Health, \\ Saint Louis University, Saint Louis, MO 63104, USA \\ ${ }^{2}$ Department of Internal Medicine, Roger Williams Medical Center, Boston University School of Medicine, \\ 825 Chalkstone Avenue, Providence, RI 02908, USA
}

Correspondence should be addressed to Nadine N. Mbuyi; nadine.mbuyi@utoronto.ca

Received 1 May 2014; Revised 2 July 2014; Accepted 2 July 2014; Published 6 August 2014

Academic Editor: Francesco Panza

Copyright (C) 2014 O. O. Olayinka and N. N. Mbuyi. This is an open access article distributed under the Creative Commons Attribution License, which permits unrestricted use, distribution, and reproduction in any medium, provided the original work is properly cited.

Objectives. To review epidemiologic studies on the prevalence, incidence, and risk factors of dementia in sub-Saharan Africa (SSA). Methods. A MEDLINE search (from January 1992 to December 31, 2013) of epidemiologic studies, with no language restriction, was conducted using the keywords "dementia" or "Alzheimer's" and "Africa." We selected for review population and hospital-based studies that reported the prevalence, incidence, or risk factors of dementia in SSA in people aged 60 years and above. References of selected articles were reviewed to identify additional relevant articles that met our selection criteria. Results. Of a total of 522 articles, 41 were selected and reviewed. The reported prevalence of dementia in SSA varied widely (range: 2.29\%-21.60\%); Alzheimer's disease was the most prevalent type of dementia. Only two studies conducted in Nigeria reported incidence data. Major risk factors identified include older age, female gender, cardiovascular disease, and illiteracy. Conclusion. Data on the epidemiology of dementia in SSA is limited. While earlier studies reported a lower prevalence of dementia in older persons, recent studies have put these findings into question suggesting that dementia prevalence rates in SSA in fact parallel data from Western countries.

\section{Introduction}

According to a recent survey conducted by Harvard School of Public Health and Alzheimer's Europe consortium on Alzheimer's disease $(\mathrm{AD})$, dementia of the Alzheimer's type is a major cause of health concern in adults [1]. A similar trend is predicted in most countries in sub-Saharan Africa (SSA) where the proportion of elderly people is expected to rise over the coming years [2]. Worldwide, the prevalence of dementia among those aged 60 years and above ranges from five to seven percent [3] and studies conducted in developed countries have consistently shown that $\mathrm{AD}$ is the most common type of dementia followed by vascular dementia (VaD) [4]. However, there are scarce and conflicting reports on the prevalence of dementia and its subtypes in SSA $[3,5,6]$, which may have far-reaching implications on public health policies on dementia in the region. While some studies suggest a lower prevalence of dementia in some parts of SSA $[3,7-10]$, other studies report prevalence rates comparable to those reported from Western countries $[6,11,12]$.

A variety of reasons may account for the varying reported prevalence rates of dementia in SSA. This is a vast territory with a population of 1.1 billion people $[13,14]$, and the number of people aged 60 years and above is projected to rise to over 67 million by 2030 [15]. The region consists of several ethnic groups, with different cultures, languages, diets, and traditions [13], which may impact the prevalence of diseases in unique ways. Additionally, the relatively high prevalence of communicable diseases such as HIV-AIDS, low life expectancy at birth, the rising prevalence of cardiovascular risk factors such as hypertension and diabetes, and low-literacy level in SSA are important factors that are also reported to influence the epidemiology of chronic diseases like dementia $[16,17]$. Further, genes play a role in the 
development of dementia and may impact its epidemiology in the genetically diverse African population [18]. The factors mentioned above, combined with the limited amount of region-wide, standardized epidemiological studies in SSA, call for a review of studies on dementia in the region. The objective of this paper is to identify the prevalence, incidence, and risk factors of dementia in SSA in order to gain a clearer view of this major public health concern.

\section{Methods}

We conducted a search of MEDLINE (from January 1st, 1992 to December 31, 2013) for epidemiologic studies using the keywords "dementia" or "Alzheimer's" and "Africa," with no restriction to language (Figure 1). Subsequently, each author reviewed the abstracts of all articles that were identified through the search. Studies were selected for further review and analysis if they satisfied the following inclusion criteria:

(1) studies that related epidemiologic data (i.e., prevalence, incidence, or risk factors) on dementia in SSA (i.e., 49 sovereign nations, 2 overseas departments of France, and 1 overseas British territory located fully or partially south of the Sahara desert) [13] (Figure 2);

(2) studies that were population or hospital based;

(3) studies that included persons aged 60 years and above;

(4) studies that used validated screening and diagnostic tools for dementia and dementia subtypes;

(5) studies describing histological findings from brain autopsies of elderly subjects.

References of selected articles were also reviewed in order to identify additional relevant articles that met our selection criteria. When there was a disagreement between the authors as to whether an article should be selected for review, a discussion took place and both authors reached a consensus.

Studies were excluded on the basis of the following exclusion criteria:

(1) studies not conducted in SSA;

(2) studies that were reviews, case reports, or case series;

(3) studies that did not relate epidemiologic data;

(4) studies that did not discuss dementia or its subtypes in individuals aged 60 years and above.

A summary of the studies that were selected is provided in Tables 1 and 2.

\section{Results}

The search yielded 522 articles. The abstracts of all the articles were reviewed and 35, that met the inclusion criteria, were selected for further review (Figure 1). Six additional articles were identified from the references of the selected articles, making a total of 41 articles that were finally reviewed. The 41 articles included one study (2.44\%) each from Burkina Faso, Cameroon, Ghana, and the Republic of Congo, two

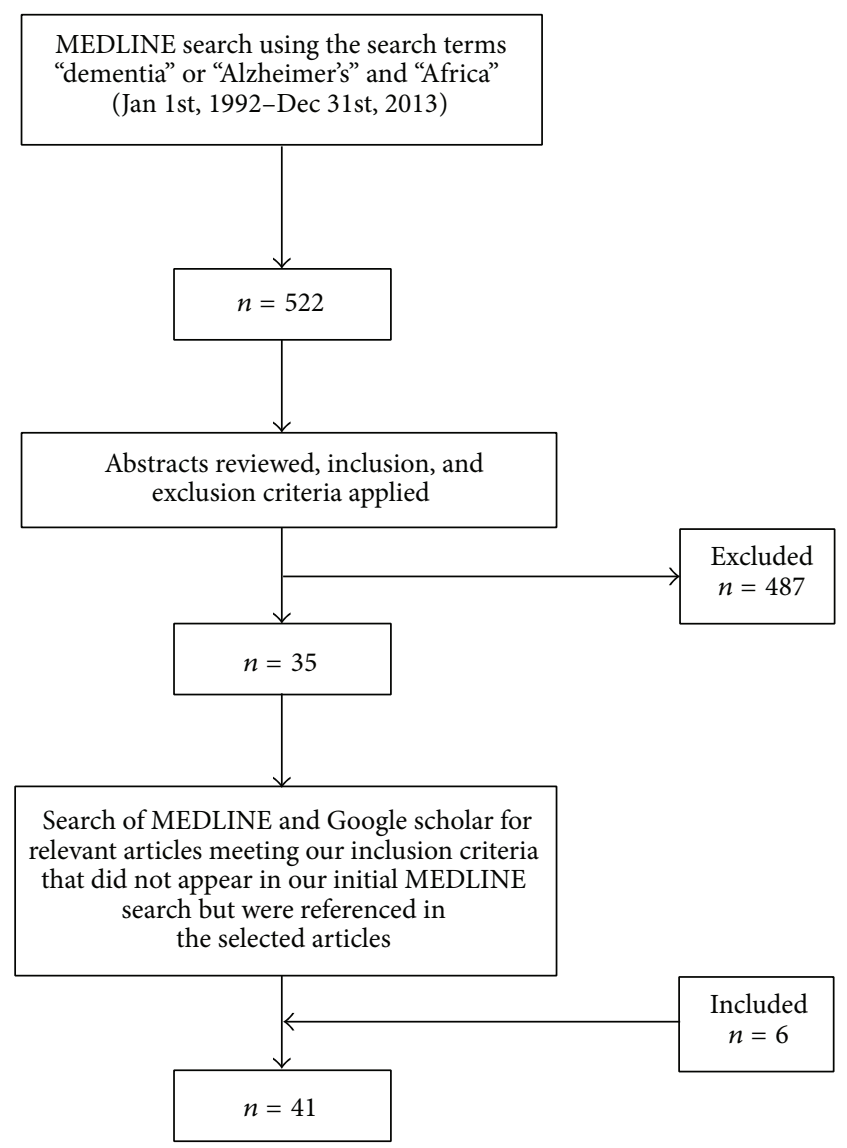

FIgURE 1: Flow chart of search methodology used to identify relevant population and hospital-based studies on the epidemiology of dementia in SSA.

studies (4.88\%) each from Benin Republic, Kenya, Senegal, and South Africa, three studies (7.32\%) from Central African Republic and Tanzania, and 23 studies (56.10\%) from Nigeria. Twenty-seven (65.85\%) studies were populationbased; thirteen (31.71\%) were hospital-based studies. Most of the population-based studies had study participants ranging from 184 persons in a Kenyan study (84 controls versus 100 demented persons) to 4,706 persons in the IndianapolisIbadan epidemiological study of dementia (2,494 NigeriaYoruba versus 2,212 African Americans in Indianapolis), while the range for hospital-based studies was 23 to 240,294 participants (Tables 1 and 2).

Overall, the reported age-adjusted prevalence of dementia for the population-based studies we reviewed varied widely ranging from $2.29 \%(\mathrm{AD}=1.41 \%)$ in Nigeria-Yoruba, aged 65 years and above, who lived in the Idikan community in Ibadan city [8], to $21.60 \%$ (AD prevalence not reported) in the rural Hai district of Tanzania (study participants aged 70 years and above) [6]. The reported prevalence of dementia for hospital-based studies ranged from $0.05 \%$ at a neuropsychiatric practice in southwestern Nigeria (survey period $1998-2007$ ) [45], to $8.87 \%$ at a geriatric center in Dakar, Senegal [51]. Further, dementia accounted for $6.90 \%$ of patients with acute confusional state in a hospital in 


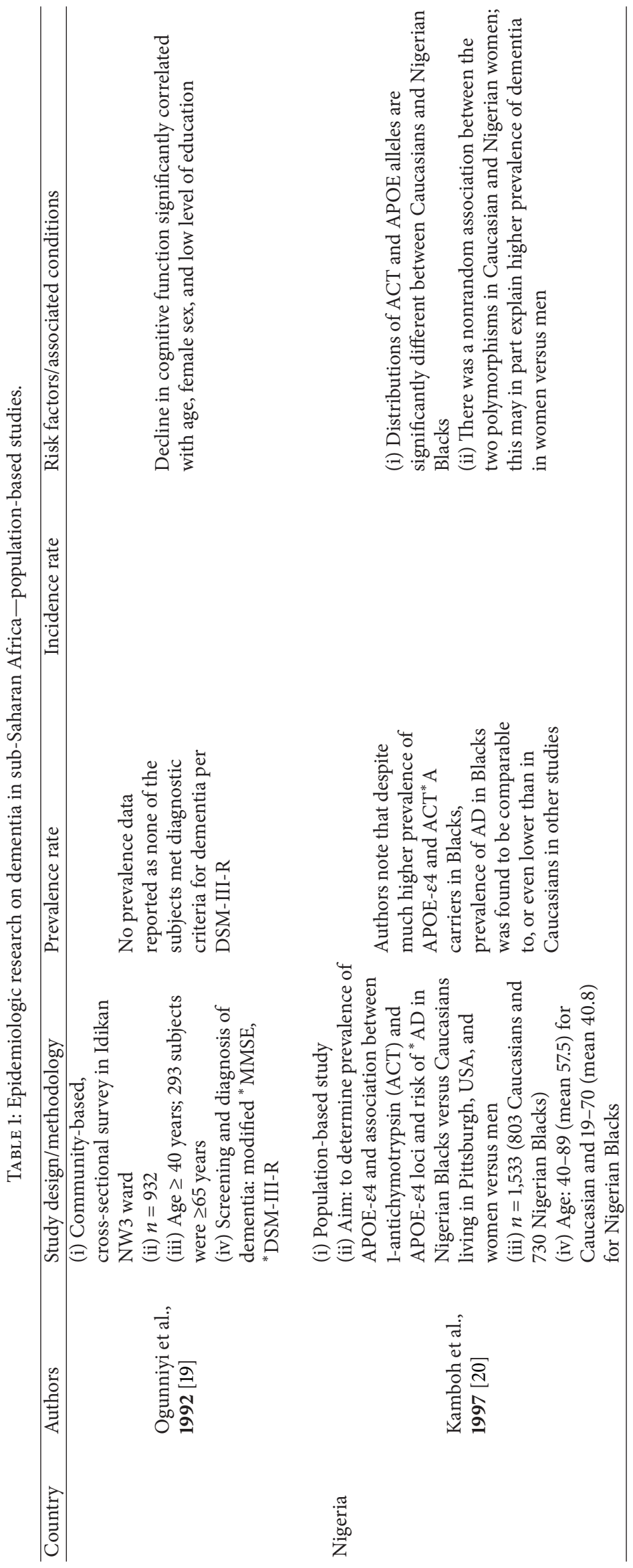




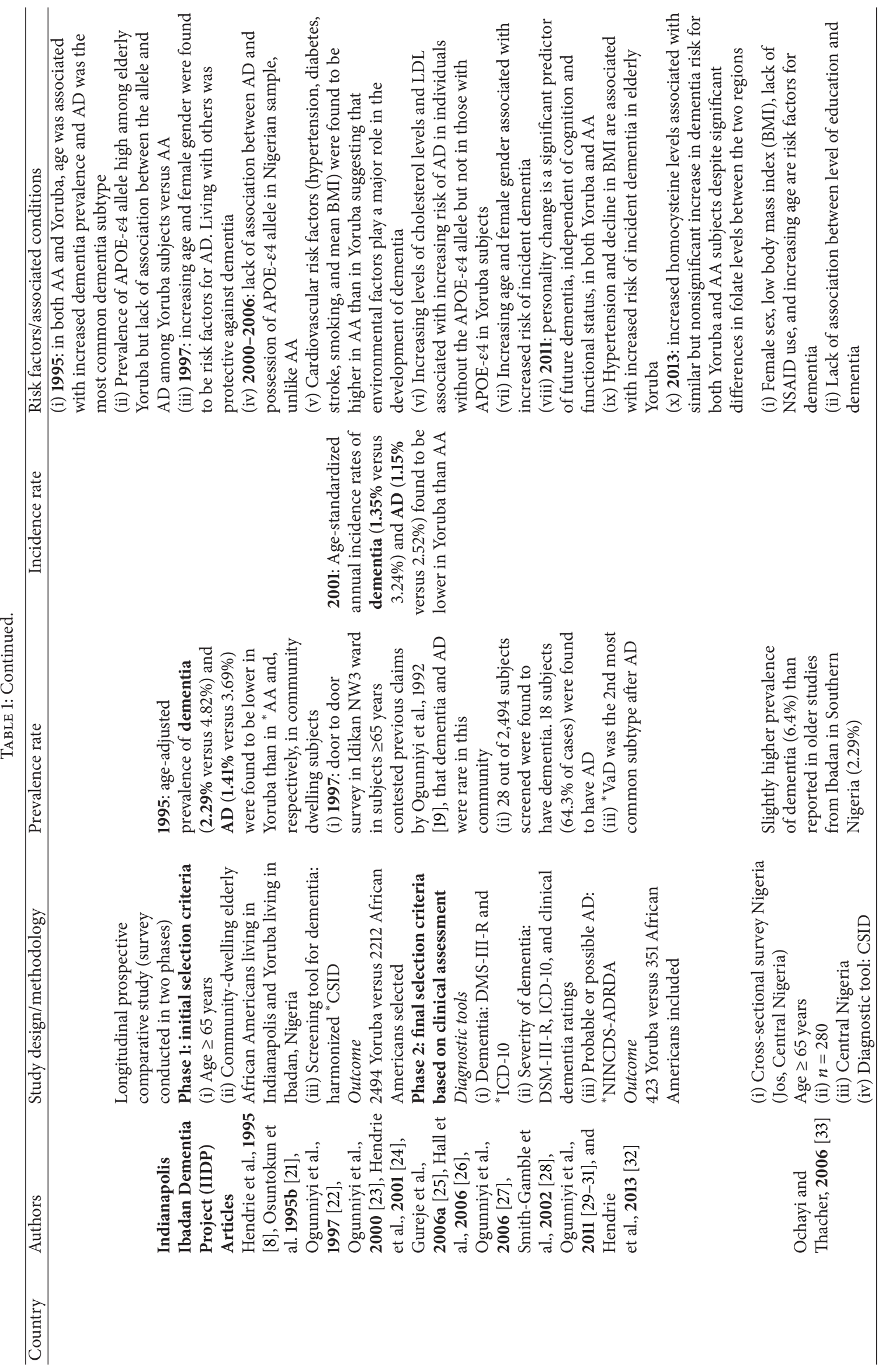




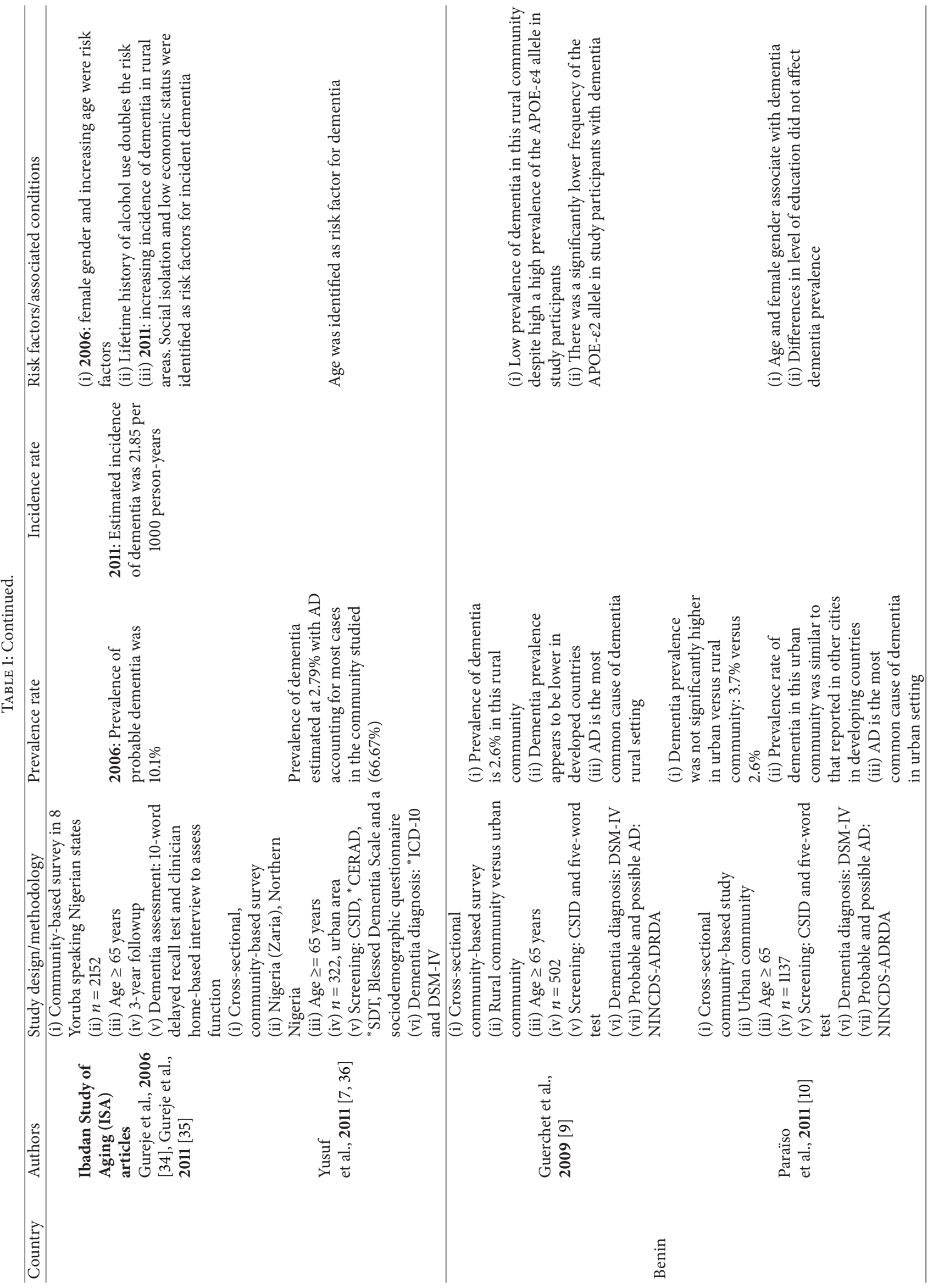




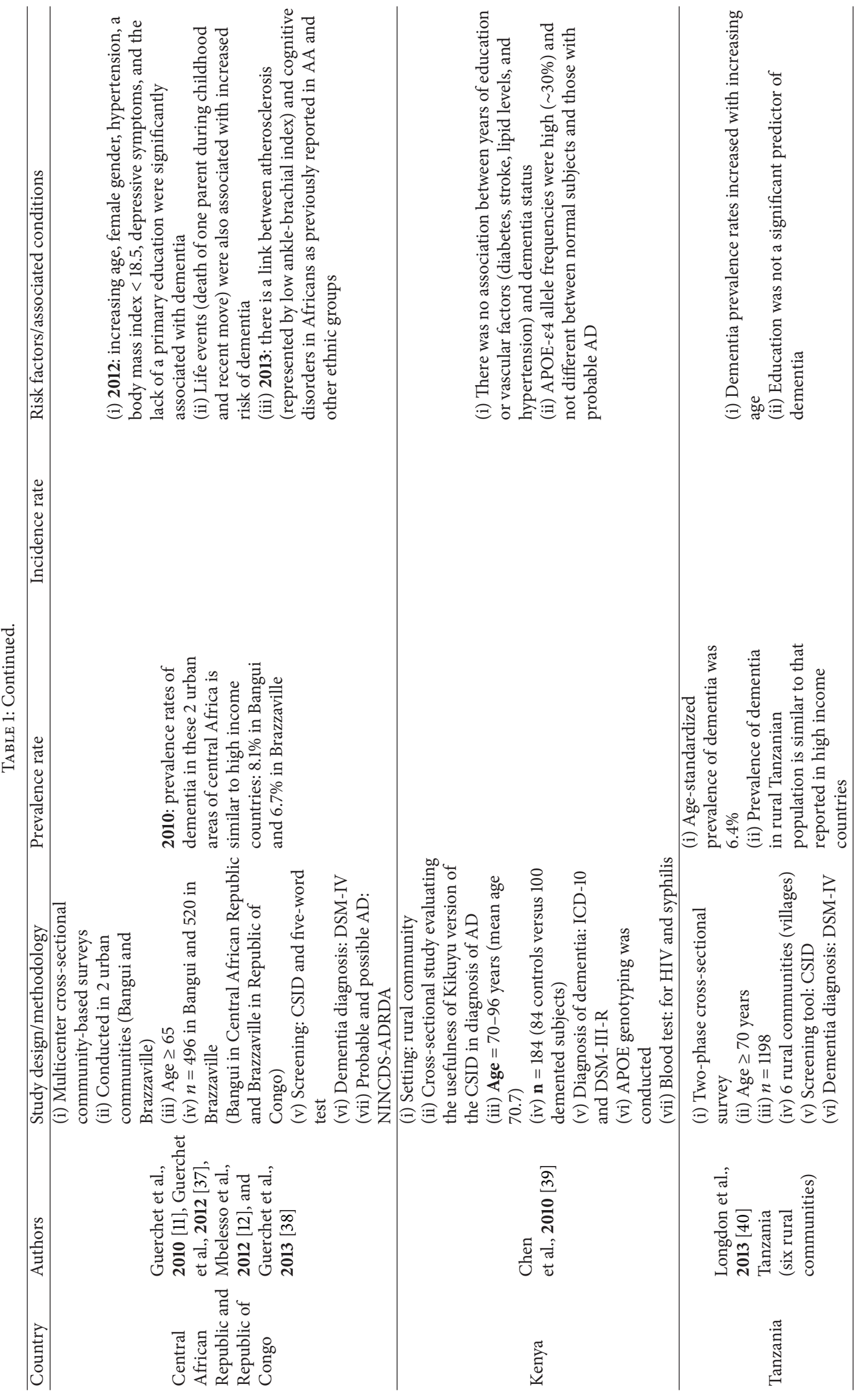




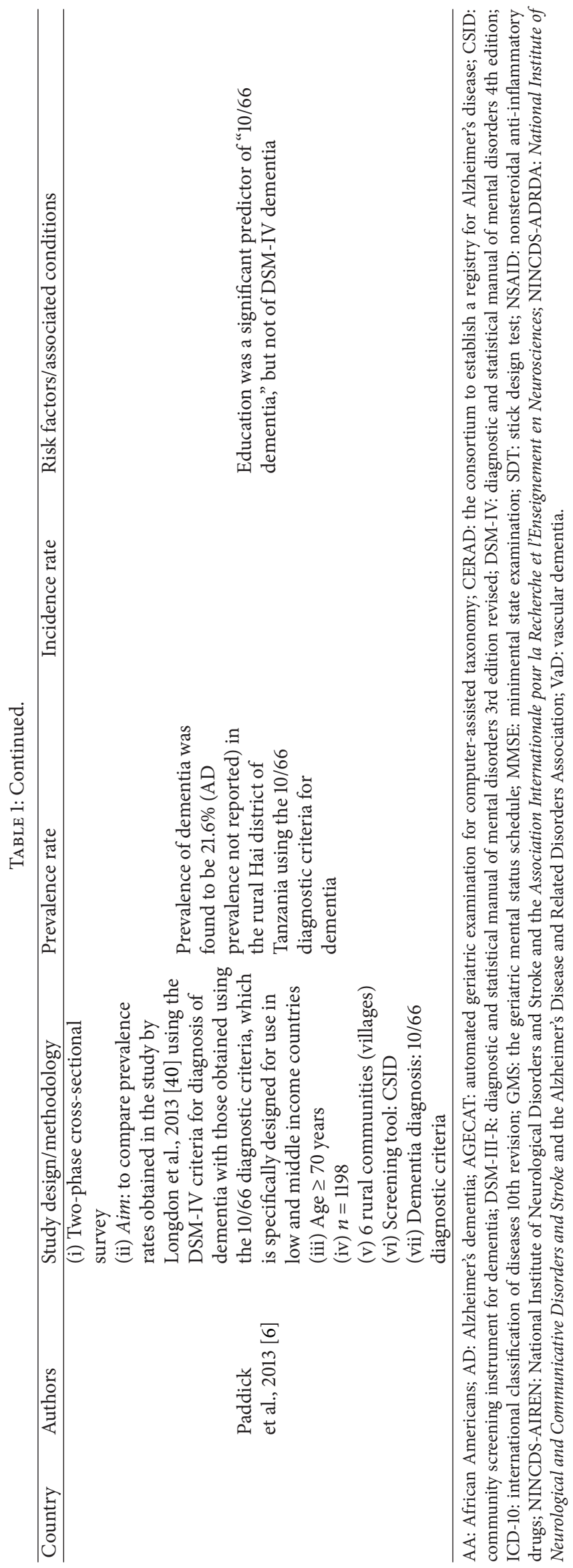




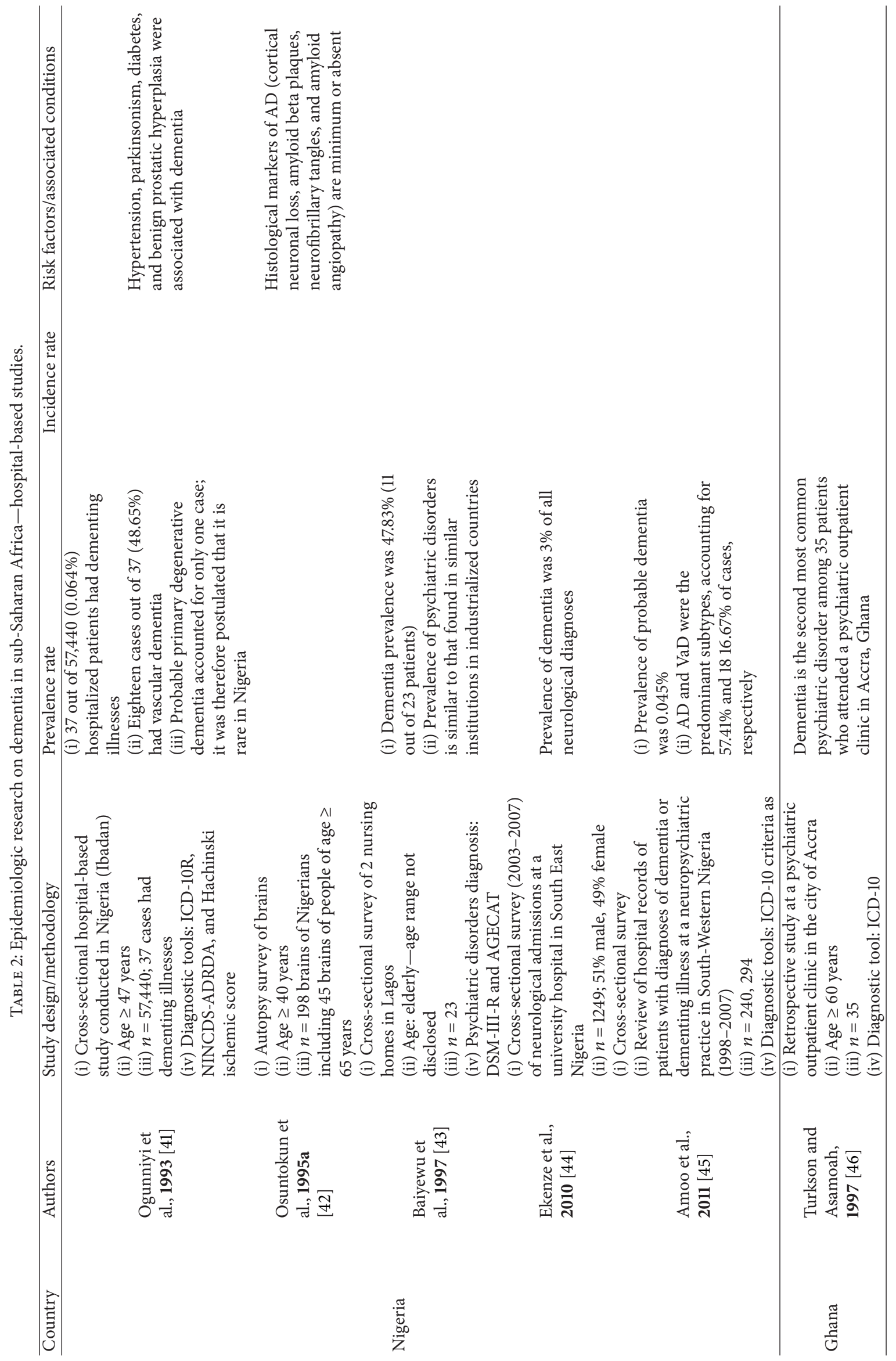




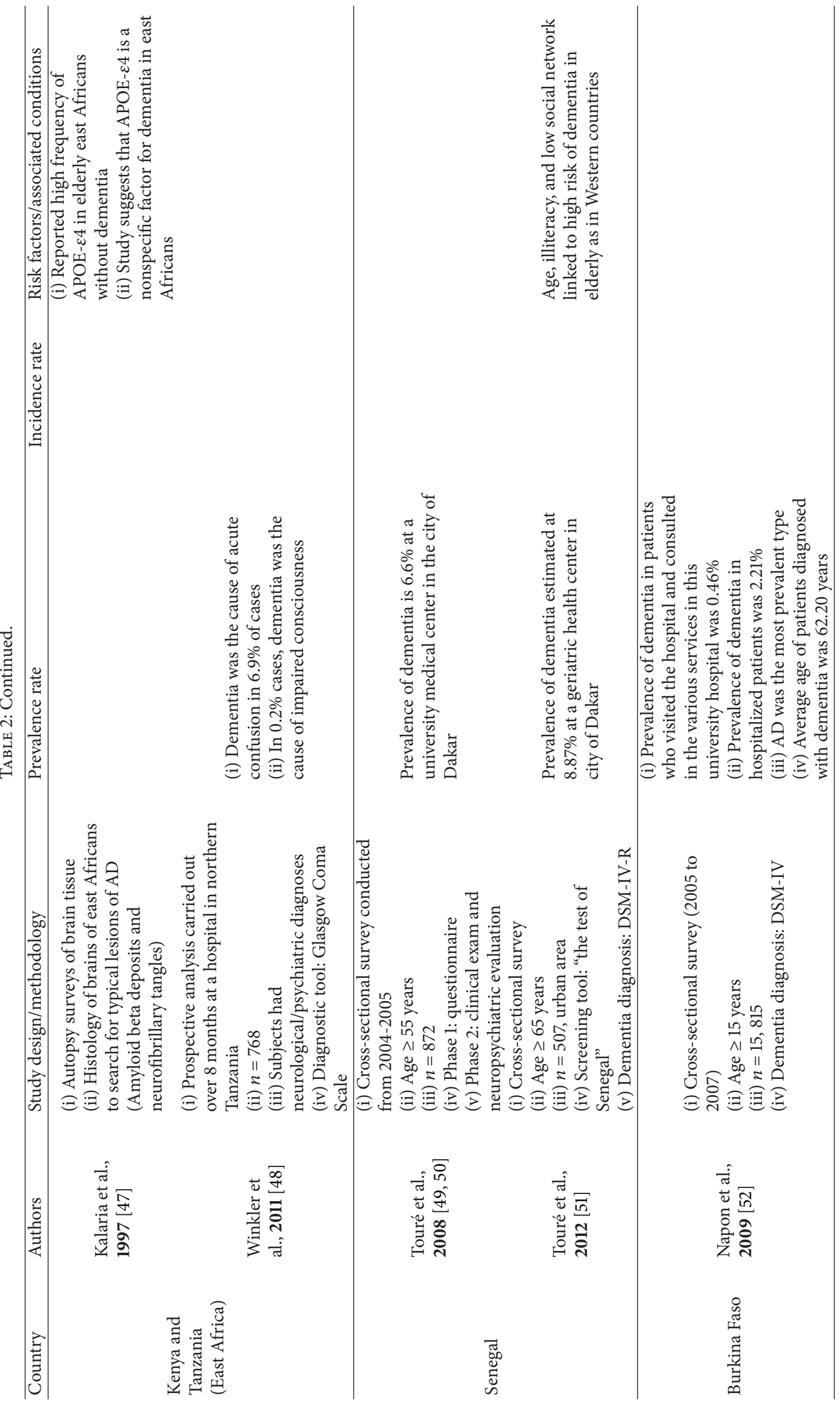



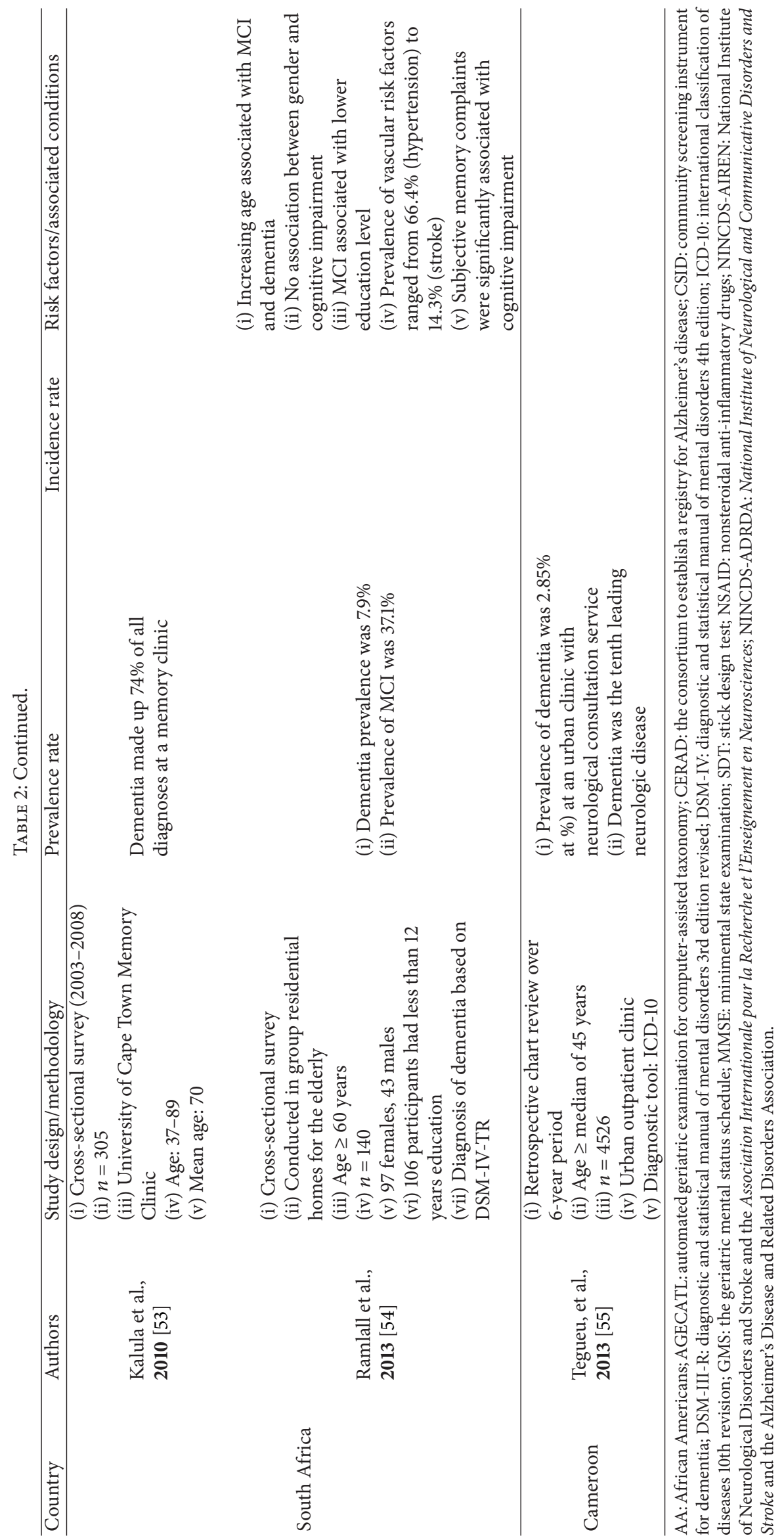


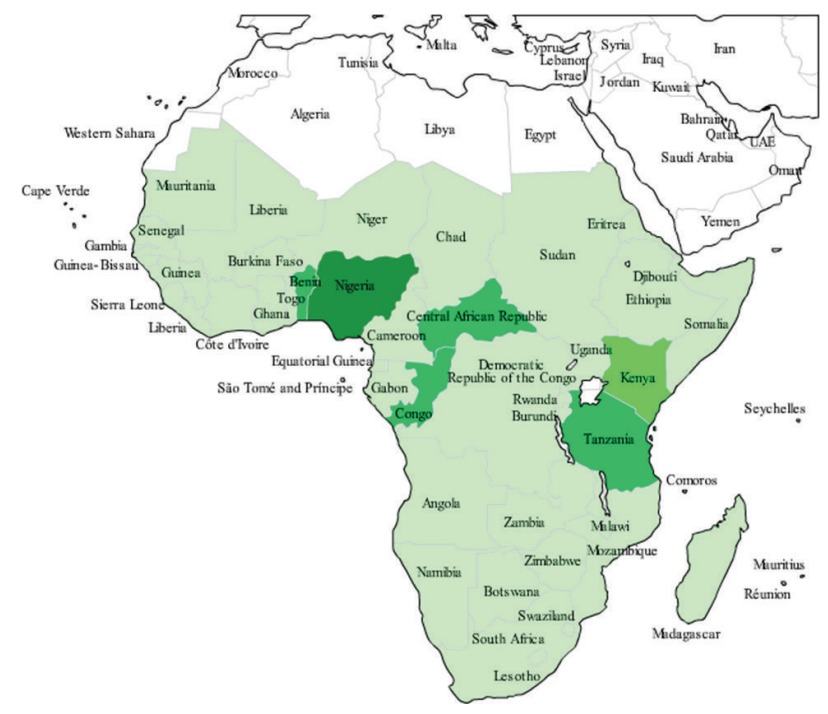

Population-based studies SSA

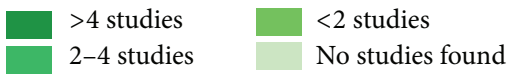

FIGURE 2: Distribution of population-based studies on the epidemiology of dementia in SSA.

Tanzania [48], while $74.00 \%$ of 305 patients who presented to a memory clinic in South Africa were diagnosed with dementia [53]. The incidence of dementia in SSA was only reported in two population-based studies both conducted in Nigeria-Yorubas. The age-standardized annual incidence rate of dementia reported by one of the studies was $1.35 \%$ $(\mathrm{AD}=1.15 \%)$ [48], while the other study reported a dementia incidence of $2.19 \%$ in a survey of 1225 Yoruba subjects, aged 65 years and above [24]. Major risk factors for dementia that were identified by most of the population-based studies included increasing age, female gender, cardiovascular disease, and low-literacy level $[6,10,35]$. In most studies, AD was the most reported dementia subtype [8-10, 22, 36, 52]. While there were reports of a high frequency of the APOE- $\varepsilon 4$ allele in Africans, most studies found no significant association between the APOE- $\varepsilon 4$ allele and dementia in SSA $[8,9]$.

3.1. Prevalence. The first community-based study we found on the prevalence of dementia in SSA was conducted in Ibadan, Nigeria, in 1992. The authors found impaired cognition in $4.4 \%$ of the 932 study participants (293 were aged 65 years and above), and none met the DSM-III-R diagnostic criteria for dementia, suggesting that dementia was a rare disease in Nigeria [19]. A year later, the authors conducted a similar but hospital-based study in which they found that 37 out of a total of 57,440 hospitalized patients had dementia [41]. Of the 37 patients, 18 (48.70\%) had vascular dementia and one $(2.70 \%)$ patient was identified as having probable primary neurodegenerative disease. Additionally, a study of 198 postmortem brains conducted at a university hospital in Ibadan revealed a paucity of histological markers of $\mathrm{AD}$ (cortical neuronal loss, amyloid beta plaques, neurofibrillary tangles, and amyloid angiopathy) [42].

In 1995, prevalence data on dementia from a collaborative project between researchers in Indianapolis, United States, and Ibadan, Nigeria, the Indianapolis Ibadan Dementia Research Project (IIDP), was reported. The authors found the prevalence of dementia in an Ibadan community to be $2.29 \%(\mathrm{AD}=1.41 \%)$ [9]. The study enrolled 2494 Yorubas and 2212 African American Indianapolis residents, aged 65 years and above. It is worth noting that the dementia screening instruments used for the Ibadan-Indianapolis study was customized to reflect the literacy level and culture of the study participants. In another well-powered, cross-sectional survey of persons who lived in the rural Djidja community of Benin, the reported prevalence of dementia was also low at $2.60 \%$ in those aged 65 years and above [9]. Two years later, a similar prevalence study conducted in the urban city of Cotonou in Benin, reported a nonsignificantly higher but comparable prevalence of 3.70\% [10]. A lower prevalence of $2.85 \%$ was also reported at a neurology clinic in Yaoundé, the capital of Cameroon, where the authors reviewed the medical records of 912 patients who visited the clinic from May 2005 to December 2011 [55]. The Cameroon finding is similar to a study conducted in eastern Nigeria where dementia accounted for $3.00 \%$ of all neurological admissions into the medical ward of a university hospital between 2003 and 2007 [44]. In northern Nigeria, the prevalence of dementia in a cross-sectional survey of 322 Hausa-Fulanis, aged 65 years and above, was $2.79 \%$ with $\mathrm{AD}$ accounting for $66.67 \%$ of cases [7].

Higher prevalence of dementia has also been reported in parts of SSA. Although this was a survey of nursing-home residents in cosmopolitan Lagos, the authors found that 11 (37.93\%) of the 29 residents had dementia, a prevalence that is close to those reported in similar institutions in Western countries [43]. Further, Turkson and Asamoah reported that dementia was the second most common diagnosis made at a psychiatric out-patient clinic in Accra, Ghana, between 1989 and 1993 in 35 patients, aged 60 years and above [46]. Additionally, a cross-sectional survey conducted in central Nigeria reported a slightly higher prevalence of dementia (6.40\%) [33] than was reported in studies conducted in Ibadan, Nigeria [8]. Two hospital-based surveys in Senegal equally reported higher prevalence rates of dementia of $6.60 \%$ (in participants aged 55 years and above) and $8.87 \%$ (participants aged 65 years and above) $[49,51]$. Similarly, a populationbased study conducted in the Central African Republic capital city of Bangui reported a dementia prevalence of $8.10 \%$, a rate that is similar to data from Western countries [12]. In 2012/13, a two-phase cross-sectional survey of six villages was conducted in the rural Hai district of Tanzania (subjects aged 70 years and above) using two different diagnostic tools for dementia, the DSM-IV and the 10/66 Dementia Research Group diagnostic criteria for dementia for low and middle income countries [6,40]. Surprisingly, a higher dementia prevalence of $21.60 \%$ was found using the 10/66 diagnostic criteria compared to a prevalence rate of $6.40 \%$ when diagnosis was based on the DSM-IV criteria $[6,40]$. 
3.2. Incidence. Only two of the studies we reviewed reported incidence data on dementia, and both were population-based longitudinal studies conducted in Ibadan, Nigeria [24, 35]. After a five-year followup, the first study reported the ageadjusted incidence of dementia in persons aged 65 years and above as $1.35 \%(\mathrm{AD}=1.15 \%)$ [24], while the estimated incidence of dementia in a similar cohort of elderly participants in a 2011 study was $2.19 \%$ after a 3-year followup [35].

3.3. Risk Factors. A fairly broad range of genetic and environmental risk factors for dementia was reported by many of the studies we reviewed. Studies conducted in Nigeria, Kenya, Tanzania, and Benin all reported a high frequency of the APOE- $\varepsilon 4$ allele (genetic risk factor for AD) in Africa $[8,9,20,25,26,39]$. Despite the high frequency of the APOE- $\varepsilon 4$ allele found in Africans, there was a general lack of association between the allele and dementia in the region $[21,25,39]$. Interestingly, Guerchet et al., in their Benin study, reported a significantly lower frequency of the APOE- $\varepsilon 2$ allele in study participants with dementia [9].

Interaction between genetic and environmental risk factors in the development of $\mathrm{AD}$ was highlighted in some studies. For instance, Hall et al. found that in Yoruba subjects who had high levels of cholesterol and LDL in conjunction with the APOE- $\varepsilon 4$ allele had a decreased risk of AD compared to subjects without the allele [26]. The effect of gene-gene interaction on dementia was reported by a study that aimed to compare the age- and gender-specific distribution of the APOE and alpha-1-antichymotrypsin (ACT) genes and the effect of this interaction on AD [20]. In this study, Kamboh et al. suggested that the higher prevalence of $\mathrm{AD}$ in both Caucasian and Black women may be due to the modifying effects that ACT has on the APOE gene. Specifically, the study found a higher frequency of the ACT ${ }^{*} \mathrm{~A}$ and APOE 4 alleles in Nigerian Blacks. Furthermore, these two alleles were found to occur "nonrandomly" in both Caucasian and Nigerian women. The authors hypothesized that the interaction between these two alleles may account for the higher prevalence of dementia observed in women [20].

Environmental factors reported to be associated with dementia in SSA include the following: increasing age, female sex, positive history of hypertension, hypercholesterolemia, diabetes mellitus, peripheral arterial disease, stroke, low level of education, diet, depressive symptoms, and low body mass index $[8,9,27,29,32,33,35,37,38,47,54]$. In an IIDP study, a comparison of smoking history and mean body mass index (BMI) showed that these factors were significantly higher in African-Americans than in the Yoruba suggesting that environmental factors play a significant role in the development of Alzheimer's dementia [23]. An additional two studies found hypertension and low BMI to be associated with an increased risk of dementia in elderly Yoruba [30, 31]. Similarly, increasing age, female gender, hypertension, low weight, living alone, and low education level were reported to be significantly associated with dementia in a survey of elderly study participants living in Bangui, Central African Republic and Brazzaville, Congo [37]. It is worth noting that Ogunniyi et al. found that self-reported hypertension was a protective factor for Alzheimer's dementia in Yorubas [27].
Increased homocysteine levels were also reported to be associated with a similar but nonsignificant increase in dementia risk for both Yoruba and African Americans although there was a significant difference in folate levels between the two sites [32]. Further, two Senegal studies linked age, illiteracy, and low social network to the development of dementia $[49,51]$. The Senegal findings are consistent with those of a cross-sectional study conducted in South Africa. The South Africa study found that participants with dementia and mild cognitive impairment were of advanced age and had less than 12 years of formal education in addition to having a higher prevalence of vascular events such as hypertension and stroke. However, this study found no significant association between the sex of participants and dementia [54]. More recently personality change was reported to be an indicator for future dementia in elderly African Americans and Nigeria-Yoruba [28].

\section{Discussion}

This review highlights the fact that the reported prevalence of dementia in SSA varies widely [56]. However, most studies suggest a lower prevalence of dementia compared to developed countries. Because age is the strongest risk factor for dementia $[57,58]$, the low prevalence of dementia reported in SSA may be associated with the low life expectancy in the region. Additionally, the paucity of epidemiologic data on dementia makes it difficult to get an overall picture of the burden of the disease in this region. Research methodology may also affect epidemiologic data [56]. For instance, some of the articles we reviewed were self-reported surveys. Employing this approach might contribute to the reported low prevalence of dementia because, in several African cultures, people with dementia and other mental health problems are often stigmatized [59]. Furthermore, only few studies provided age-adjusted rates for dementia despite differences in the age-structure of countries in SSA [15]. Therefore, inferences based on a comparison of crude prevalence data on dementia across studies may be misleading. For hospitalbased studies, low utilization of healthcare facilities by the elderly might have contributed to the reported low prevalence rates of dementia.

Various cultures and languages exist within and between countries in SSA. This may also pose a special challenge for researchers working on dementia who adopt standardized dementia screening tools that were originally developed for Western societies [60]. Most of the studies included in our review used standardized screening tools for dementia in accordance with internationally recognized guidelines. However, some researchers customized these screening tools to the culture, language, and literacy level of study participants, as was the case with the IIDP and the "test of Senegal," a dementia-screening tool [50], among other studies [6, 8, $34,35]$. This approach is novel and could be considered in developing a harmonized screening tool for dementia in SSA in the future.

Similarly, identifying risk factors for dementia in SSA is critical. The finding that there was a lack of association between the APOE- $\varepsilon 4$ allele and dementia appears to be 
unique to the African population as the presence of this allele has been associated with a higher prevalence of $\mathrm{AD}$ in Caucasians and African Americans [25, 39]. In fact, Hall et al. found a higher risk for AD in subject participants with high cholesterol and LDL levels who lack the APOE- $\varepsilon 4$ allele [26]. Additionally, the finding that the absence of the APOE- $\varepsilon 2$ allele in study participants in Benin is significantly associated with dementia, and cognitive impairment is unique and calls attention to the role that genes play in the prevalence of dementia in specific SSA populations [9]. Further, urban versus rural living was found to be associated with dementia. While two studies conducted in Benin found a nonsignificantly lower prevalence of dementia in the rural Djidja community $(2.60 \%)$ compared to the urban city of Cotonou, Benin, (3.70\%) [9, 10], Gureje et al. [35] found rural living to be associated with an increasing incidence of dementia in southwestern Nigeria [35]. Correlations between different cardiovascular risk factors and dementia were also reported in some studies. For instance, Guerchet et al. attributed the higher prevalence of dementia in two urban cities of central Africa to hypertension, among other risk factors [37]. The lower prevalence of cardiovascular diseases and diabetes in Yoruba compared to African Americans living in Indianapolis was also suggested to play a role in the low prevalence of dementia in Yorubas [23]. The Yoruba diet which is low in calories, fat, and salt but high in fiber and ascorbic acid was also identified as being protective against AD [61]. Overall, the studies reviewed suggest that genetic and environmental factors also affect the epidemiology of dementia in SSA. However, further research into the association between these factors and dementia should be encouraged.

4.1. Strengths and Limitations. This review provides an overview of the scope of epidemiologic studies conducted on dementia in SSA. To that effect, both community and hospital-based studies conducted over the last twenty-two years were included in our analysis. In addition to presenting prevalence data, we also reviewed available data on the incidence and risk factors (including genetic and environmental factors) of dementia in SSA. However, we identified some limitations. For instance, our initial search was limited to the MEDLINE database and might have excluded some relevant work. We addressed this issue by reviewing references of articles identified through our initial search. Finally, because most of the studies we found were conducted in single communities in various countries across SSA, the results lack external validity.

\section{Conclusion}

This review of published work on the epidemiology of dementia in older persons in SSA suggests that research in this area is limited. Most of the population-based studies were in single communities and may not be representative of the country in which they were conducted. Overall, earlier studies reported a lower prevalence of dementia, while recent studies have put these findings into question suggesting that dementia prevalence rates in SSA may in fact be similar to
Western countries. Based on these observations, more epidemiologic studies that are representative of the SSA population should be encouraged. This may involve collaborative projects between researchers within and between SSA countries. For instance, comparison of genetic polymorphisms between different communities in the region may unravel subtle factors that contribute to the epidemiology of dementia. The use of a harmonized screening tool for dementia that accounts for differences in literacy levels and sociocultural characteristics is also suggested. This would require dementia researchers in SSA to work together. In other regions of the world, dementia has been established as a disease of high economic and public health significance. As the population of the elderly is predicted to rise globally, the burden of dementia in SSA is likely to increase. Therefore, stakeholders in public health in the region are advised to map out strategies to tackle this important public health issue.

\section{Conflict of Interests}

The authors declare that there is no conflict of interests regarding the publication of this paper.

\section{Authors' Contribution}

Olaniyi O. Olayinka and Nadine N. Mbuyi equally contributed to the study conception and design, literature search, data extraction, analysis, and interpretation, and drafting of the paper.

\section{References}

[1] R. J. Blendon, J. M. Benson, E. M. Wikler et al., "The impact of experience with a family member with Alzheimer's disease on views about the disease across five countries," International Journal of Alzheimer's Disease, vol. 2012, Article ID 903645, 9 pages, 2012.

[2] L. Fratiglioni, D. de Ronchi, and H. Agüero-Torres, "Worldwide prevalence and incidence of dementia," Drugs and Aging, vol. 15, no. 5, pp. 365-375, 1999.

[3] M. Prince, R. Bryce, E. Albanese, A. Wimo, W. Ribeiro, and C. P. Ferri, "The global prevalence of dementia: a systematic review and metaanalysis," Alzheimer's and Dementia, vol. 9, no. 1, pp. 63-75, 2013.

[4] S. F. U. Akter, M. F. A. Rani, M. S. Nordin, J. Ab Rahman, M. A. B. Aris, and M. Y. Rathor, "Dementia: prevalence and risk factors," International Review of Social Sciences and Humanities, vol. 2, no. 2, pp. 176-184, 2012.

[5] C. P. Ferri, M. Prince, C. Brayne et al., "Global prevalence of dementia: a Delphi consensus study," The Lancet, vol. 366, no. 9503, pp. 2112-2117, 2005.

[6] S. Paddick, A. R. Longdon, A. Kisoli et al., "Dementia prevalence estimates in sub-Saharan Africa: comparison of two diagnostic criteria," Global Health Action, vol. 6, pp. 1-7, 2013.

[7] A. J. Yusuf, O. Baiyewu, T. L. Sheikh, and A. U. Shehu, "Prevalence of dementia and dementia subtypes among communitydwelling elderly people in northern Nigeria," International Psychogeriatrics, vol. 23, no. 3, pp. 379-386, 2011.

[8] H. C. Hendrie, B. O. Osuntokun, K. S. Hall et al., "Prevalence of Alzheimer's disease and dementia in two communities: 
Nigerian Africans and African Americans," The American Journal of Psychiatry, vol. 152, no. 10, pp. 1485-1492, 1995.

[9] M. Guerchet, D. Houinato, M. N. Paraiso et al., "Cognitive impairment and dementia in elderly people living in rural Benin, West Africa," Dementia and Geriatric Cognitive Disorders, vol. 27, no. 1, pp. 34-41, 2009.

[10] M. N. Paraïso, M. Guerchet, J. Saizonou et al., "Prevalence of dementia among elderly people living in cotonou, an urban area of benin (West Africa)," Neuroepidemiology, vol. 36, no. 4, pp. 245-251, 2011.

[11] M. Guerchet, P. M'belesso, A. M. Mouanga et al., "Prevalence of dementia in elderly living in two cities of central africa: the EDAC survey," Dementia and Geriatric Cognitive Disorders, vol. 30, no. 3, pp. 261-268, 2010.

[12] P. Mbelesso, A. Tabo, M. Guerchet et al., "Epidemiology of dementia in elderly living in the 3rd borough of Bangui (Central African Republic)," Bulletin de la Société de Pathologie Exotique, vol. 105, no. 5, pp. 388-395, 2012.

[13] United Nations Statistics Divisions, Composition of Macro Geographical (Continental) Regions, Geographical Sub-Regions, and Selected Economic and Other Groupings, 2010, http://unstats.un .org/unsd/methods/m49/m49regin.htm.

[14] United Nations Populations Fund, "UNFPA global and regional programme, 2008-2011," 2007, http://www.unfpa.org/worldwide/africa.html.

[15] V. A. Velkoff and P. R. Kowal, "Aging in sub-saharan Africa: the changing demography of the region: panel on policy research and data needs to meet the challenge of aging in Africa," in Aging in Sub-Saharan Africa: Recommendation for Furthering Research, B. Cohen and J. Menken, Eds., National Academies Press, Washington, DC, USA, 2006.

[16] E. Breuer, L. Myer, H. Struthers, and J. A. Joska, "HIV/AIDS and mental health research in sub-Saharan Africa: a systematic review," African Journal of AIDS Research, vol. 10, no. 2, pp. 101122, 2011.

[17] J. C. Scott, S. P. Woods, C. L. Carey, E. Weber, M. W. Bondi, and I. Grant, "Neurocognitive consequences of HIV infection in older adults: an evaluation of the "Cortical" hypothesis," AIDS and Behavior, vol. 15, no. 6, pp. 1187-1196, 2011.

[18] E. J. Parra, A. Marcini, J. Akey et al., "Estimating African American admixture proportions by use of population-specific alleles," The American Journal of Human Genetics, vol. 63, no. 6, pp. 1839-1851, 1998.

[19] A. O. Ogunniyi, B. O. Osuntokun, U. B. Lekwauwa, and Z. F. Falope, "Rarity of dementia (by DSM-III-R) in an urban community in Nigeria," East African Medical Journal, vol. 69, no. 2, pp. 64-68, 1992.

[20] M. I. Kamboh, D. K. Sanghera, C. E. Aston et al., "Genderspecific nonrandom association between the alpha 1-antichymotrypsin and apolipoprotein E polymorphisms in the general population and its implication for the risk of Alzheimer's disease," Genetic Epidemiology, vol. 14, no. 2, pp. 169-180, 1997.

[21] B. O. Osuntokun, A. Sahota, A. O. Ogunniyi et al., "Lack of an association between apolipoprotein E epsilon 4 and Alzheimer's disease in elderly Nigerians," Annals of Neurology, vol. 38, no. 3, pp. 463-465, 1995.

[22] A. Ogunniyi, O. Gureje, O. Baiyewu et al., "Profile of dementia in a Nigerian community-types, pattern of impairment, and severity rating," Journal of the National Medical Association, vol. 89, no. 6, pp. 392-396, 1997.

[23] A. Ogunniyi, O. Baiyewu, O. Gureje et al., "Epidemiology of dementia in Nigeria: results from the Indianapolis-Ibadan study," European Journal of Neurology, vol. 7, no. 5, pp. 485-490, 2000.

[24] H. C. Hendrie, A. Ogunniyi, K. S. Hall et al., "Incidence of dementia and Alzheimer disease in 2 communities: yoruba residing in Ibadan, Nigeria, and African Americans residing in Indianapolis, Indiana," Journal of the American Medical Association, vol. 285, no. 6, pp. 739-747, 2001.

[25] O. Gureje, A. Ogunniyi, O. Baiyewu et al., "APOE $\varepsilon 4$ is not associated with Alzheimer's disease in elderly Nigerians," Annals of Neurology, vol. 59, no. 1, pp. 182-185, 2006.

[26] K. Hall, J. Murrell, A. Ogunniyi et al., "Cholesterol, APOE genotype, and Alzheimer disease: an epidemiologic study of Nigerian Yoruba," Neurology, vol. 66, no. 2, pp. 223-227, 2006.

[27] A. Ogunniyi, K. S. Hall, O. Gureje et al., "Risk factors for incident Alzheimer's disease in African Americans and Yoruba," Metabolic Brain Disease, vol. 21, no. 2-3, pp. 224-229, 2006.

[28] V. Smith-Gamble, O. Baiyewu, A. J. Perkins et al., "Informant reports of changes in personality predict dementia in a population-based study of elderly African Americans and Yoruba," The American Journal of Geriatric Psychiatry, vol. 10, no. 6, pp. 724-732, 2002.

[29] A. Ogunniyi, S. Gao, F. W. Unverzagt et al., "Weight Loss and incident dementia in elderly Yoruba Nigerians: a 10-year followup study," International Psychogeriatrics, vol. 23, no. 3, pp. 387394, 2011.

[30] A. Ogunniyi, S. Gao, F. W. Unverzagt et al., "Weight Loss and incident dementia in elderly Yoruba Nigerians: a 10-year followup study," Psychogeriatrics, vol. 23, no. 3, pp. 387-394, 2011.

[31] A. Ogunniyi, K. A. Lane, O. Baiyewu et al., "Hypertension and incident dementia in community-dwelling elderly Yoruba Nigerians," Acta Neurologica Scandinavica, vol. 124, no. 6, pp. 396-402, 2011.

[32] H. C. Hendrie, O. Baiyewu, K. A. Lane et al., "Homocysteine levels and dementia risk in Yoruba and African Americans," International Psychogeriatrics, vol. 25, no. 11, pp. 1859-1866, 2013.

[33] B. Ochayi and T. D. Thacher, "Risk factors for dementia in central Nigeria," Aging and Mental Health, vol. 10, no. 6, pp. 616620, 2006.

[34] O. Gureje, A. Ogunniyi, and L. Kola, "The profile and impact of probable dementia in a sub-Saharan African community: results from the Ibadan study of aging," Journal of Psychosomatic Research, vol. 61, no. 3, pp. 327-333, 2006.

[35] O. Gureje, A. Ogunniyi, L. Kola, and T. Abiona, "Incidence of and risk factors for dementia in the Ibadan study of aging," Journal of the American Geriatrics Society, vol. 59, no. 5, pp. 869874, 2011.

[36] A. J. Yusuf, O. Baiyewu, T. L. Sheikh, and A. U. Shehu, "Prevalence of dementia and dementia subtypes among communitydwelling elderly people in Northern Nigeria," International Psychogeriatrics, vol. 23, no. 3, pp. 379-386, 2011.

[37] M. Guerchet, A. M. Mouanga, P. M’belesso et al., "Factors associated with dementia among elderly people living in two cities in Central Africa: the EDAC multicenter study," Journal of Alzheimer's Disease, vol. 29, no. 1, pp. 15-24, 2012.

[38] M. Guerchet, P. Mbelesso, A. M. Mouanga et al., "Association between a low ankle-brachial index and dementia in a general elderly population in Central Africa (epidemiology of dementia in Central Africa study)," Journal of the American Geriatrics Society, vol. 61, no. 7, pp. 1135-1140, 2013.

[39] C. Chen, T. Mizuno, R. Elston et al., "A comparative study to screen dementia and APOE genotypes in an ageing East African 
population," Neurobiology of Aging, vol. 31, no. 5, pp. 732-740, 2010.

[40] A. R. Longdon, S. Paddick, A. Kisoli et al., "The prevalence of dementia in rural Tanzania: a cross-sectional community-based study," International Journal of Geriatric Psychiatry, vol. 28, no. 7, pp. 728-737, 2013.

[41] A. Ogunniyi, U. G. Lekwauwa, Z. F. Falope, and B. O. Osuntokun, "Clinically-diagnosed dementing illnesses in Ibadan: features, types and associated conditions," African Journal of Medicine and Medical Sciences, vol. 22, no. 3, pp. 61-64, 1993.

[42] B. O. Osuntokun, A. Ogunniyi, T. A. Junaid, and U. G. Lekwauwa, "Autopsy survey for Alzheimer's disease in Nigerian Africans: a preliminary report," African Journal of Medicine and Medical Sciences, vol. 24, no. 1, pp. 75-79, 1995.

[43] O. Baiyewu, J. D. Adeyemi, and A. Ogunnniyi, "Psychiatric disorders in Nigerian nursing home residents," International Journal of Geriatric Psychiatry, vol. 12, no. 12, pp. 1146-1150, 1997.

[44] O. S. Ekenze, I. O. Onwuekwe, and B. A. Ezeala Adikaibe, "Profile of neurological admissions at the University of Nigeria Teaching Hospital Enugu," Nigerian Journal of Medicine, vol. 19, no. 4, pp. 419-422, 2010.

[45] G. Amoo, R. O. Akinyemi, L. U. Onofa et al., "Profile of clinically-diagnosed dementias in a neuropsychiatric practice in Abeokuta, South-Western Nigeria," African Journal of Psychiatry, vol. 14, no. 5, pp. 377-381, 2011.

[46] S. N. Turkson and V. Asamoah, "Common psychiatric disorders among the elderly attending a general psychiatric out patient clinic in Accra, Ghana: a five year retrospective study (19891993)," West African Journal of Medicine, vol. 16, no. 3, pp. 146149, 1997.

[47] R. N. Kalaria, J. A. Ogeng', N. B. Patel et al., "Evaluation of risk factors for Alzheimer's disease in elderly East Africans," Brain Research Bulletin, vol. 44, no. 5, pp. 573-577, 1997.

[48] A. S. Winkler, A. Tluway, and E. Schmutzhard, "Aetiologies of altered states of consciousness: a prospective hospital-based study in a series of 464 patients of northern Tanzania," Journal of the Neurological Sciences, vol. 300, no. 1-2, pp. 47-51, 2011.

[49] K. Touré, M. Coumé, D. Ndiaye-Ndongo et al., "Prévalence de la démence dans une population de personnes âgèes sénégalaises," African Journal of Neurological Sciences, vol. 27, no. 2, pp. 30-43, 2008.

[50] K. Touré, M. Coumé, N. D. Ndiaye-Ndongo et al., "Le test du Sénégal: un instrument valide et fiable pour le dépistage de la démence dans une population de personnes âgées sénégalaises," African Journal of Neurological Sciences, vol. 27, no. 1, pp. 4-13, 2008.

[51] K. Touré, M. Coumé, M. Ndiaye et al., "Risk factors for dementia in a Senegalese elderly population aged 65 years and over," Dementia and Geriatric Cognitive Disorders Extra, vol. 2, no. 1, pp. 160-168, 2012.

[52] C. Napon, S. I. S. Traore, A. Niakara, G. J. Ouango, A. Kabré, and J. Kabore, "Les démences en Afrique subsaharienne : aspects cliniques et étiologiques en milieu hospitalier à Ouagadougou (Burkina Faso)," African Journal of Neurological Sciences, vol. 28, no. 1, 2009.

[53] S. Z. Kalula, M. Ferreira, K. G. F. Thomas, L. de Villiers, J. A. Joska, and L. N. Geffen, "Profile and management of patients at a memory clinic," South African Medical Journal, vol. 100, no. 7, pp. 449-451, 2010.

[54] S. Ramlall, J. Chipps, B. J. Pillay, and A. I. Bhigjee, "Mild cognitive impairment and dementia in a heterogeneous elderly population: prevalence and risk profile," African Journal of Psychiatry, vol. 16, no. 6, 2013.

[55] C. K. Tegueu, S. Nguefack, J. Doumbe, Y. F. Fogang, P. C. Mbonda, and E. Mbonda, "The spectrum of neurological disorders presenting at a neurology clinic in yaoundé, Cameroon," The Pan African Medical Journal, vol. 14, 2013.

[56] M. Prince, "Methodological issues for population based research into dementia in developing countries. A position paper from the 10/66 Dementia Research Group," International Journal of Geriatric Psychiatry, vol. 15, no. 1, pp. 21-30, 2000.

[57] L. Launer, K. Andersen, M. Dewey et al., "Rates and risk factors for dementia and Alzheimer's disease results from EURODEM pooled analyses," Neurology, vol. 52, no. 1, pp. 78-84, 1999.

[58] B. Stephan and C. Brayne, "Prevalence and projections of dementia," in Excellence in Dementia Care: Research into Practice, M. Downs and B. Bowers, Eds., pp. 9-34, Open University Press, Maidenhead, UK, 2008.

[59] A. Okasha, "Mental health in Africa: the role of the WPA," World Psychiatry, vol. 1, no. 1, pp. 32-35, 2002.

[60] N. B. Anderson, R. A. Bulatao, and B. Cohen, Eds., Critical Perspectives on Racial and Ethnic Differences in Health in Late Life, National Research Council, National Academic Press, Washington, DC, USA, 2004.

[61] H. C. Hendrie, "Exploration of environmental and genetic risk factors for Alzheimer's disease: the value of cross-cultural studies," Current Directions in Psychological Science, vol. 10, no. 3, pp. 98-101, 2001. 


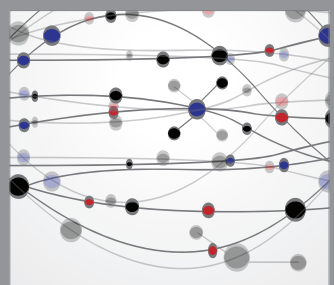

The Scientific World Journal
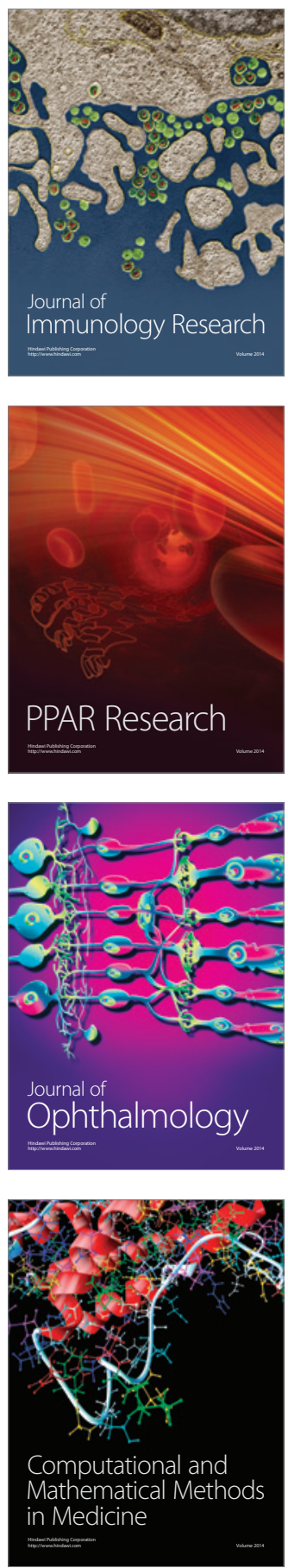

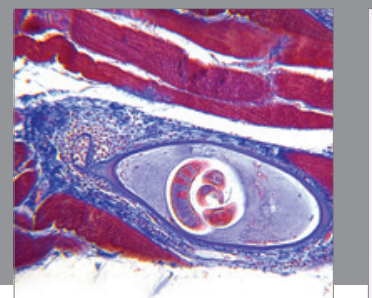

Gastroenterology

Research and Practice
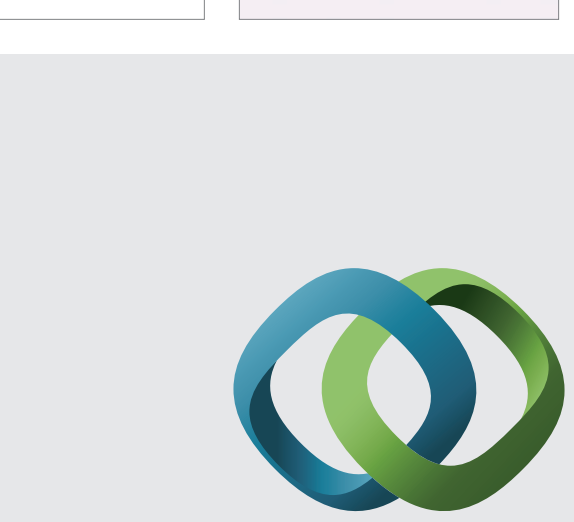

\section{Hindawi}

Submit your manuscripts at

http://www.hindawi.com
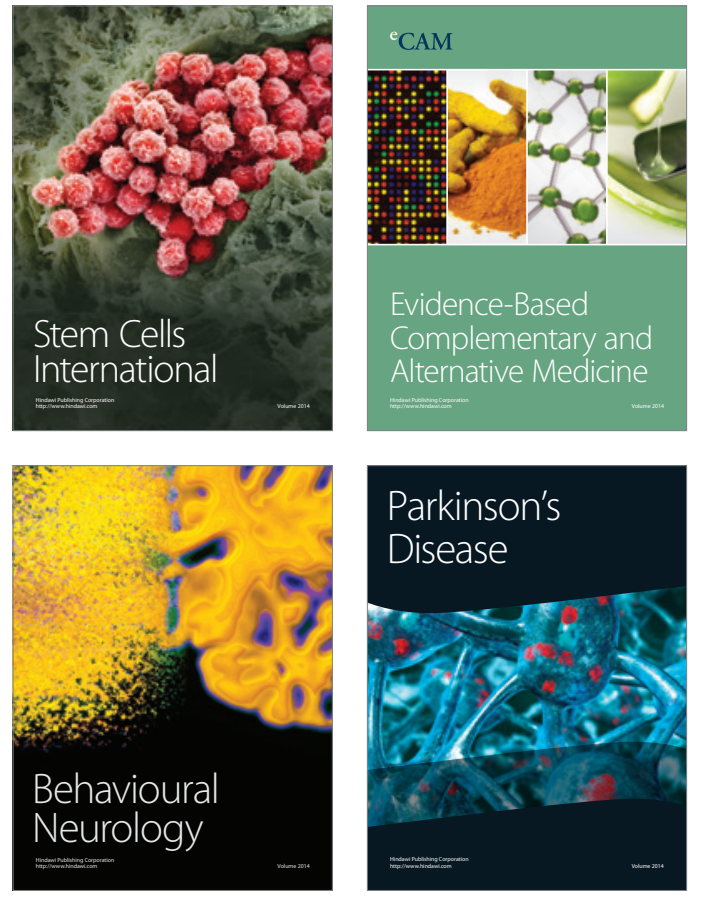
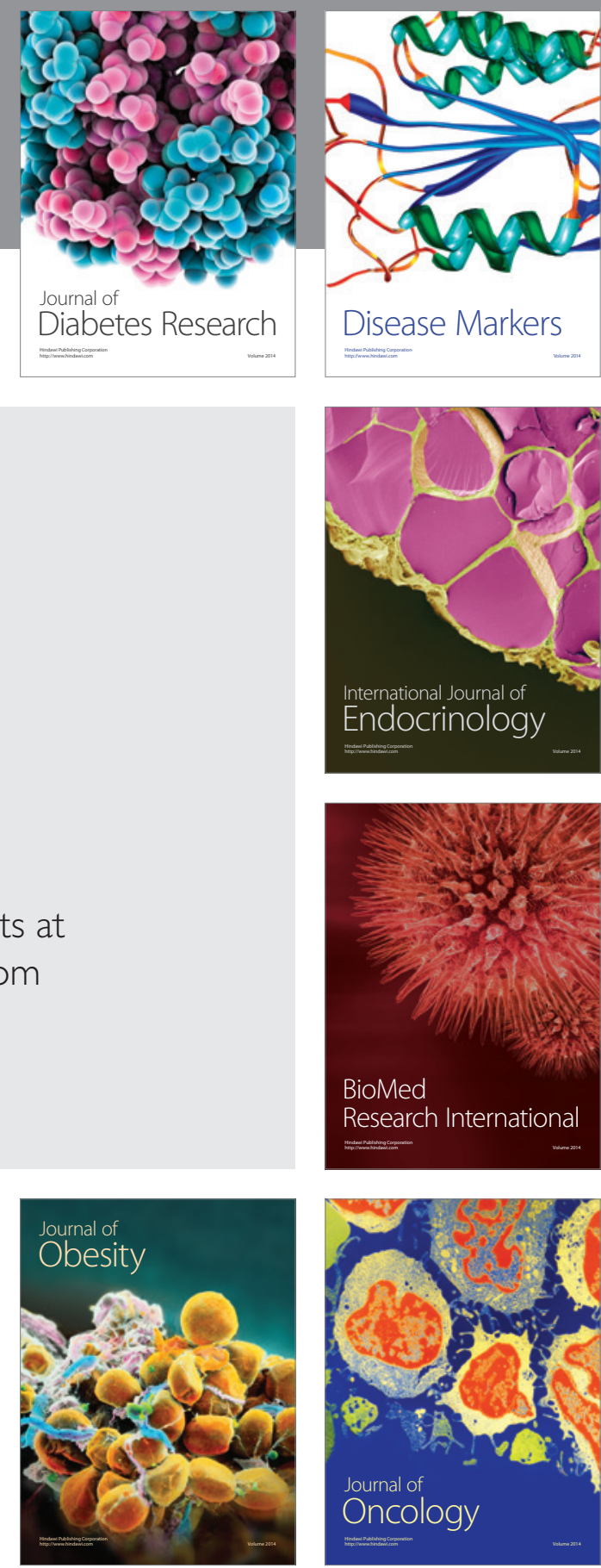

Disease Markers
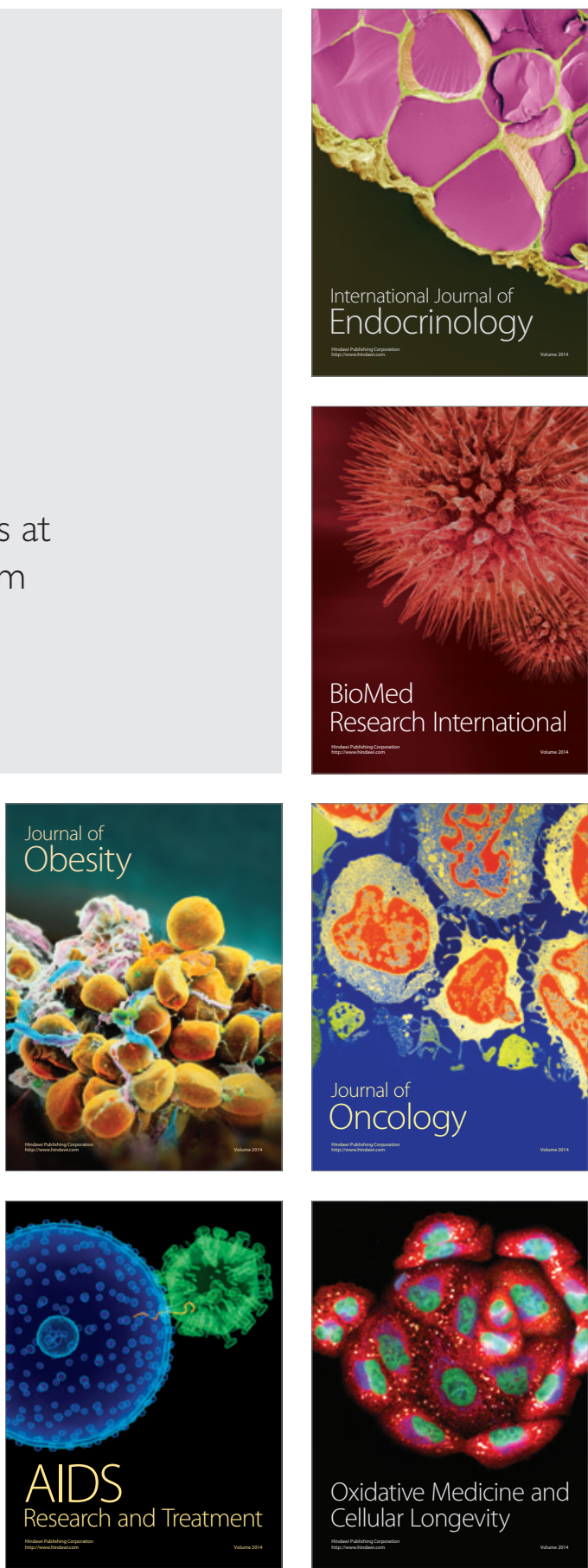